\title{
Characteristics of Preterm Neonates Treated with Surfactant in Tu Du Hospital, Vietnam
}

\author{
Ngo Minh Xuan* \\ Pham Ngoc Thach University of Medicine, Ho Chi Minh city, Vietnam
}

*Corresponding author: Ngo Minh Xuan, Pham Ngoc Thach Medical University, 2 Duong Quang Trung street, Ho Chi Minh City, Vietnam

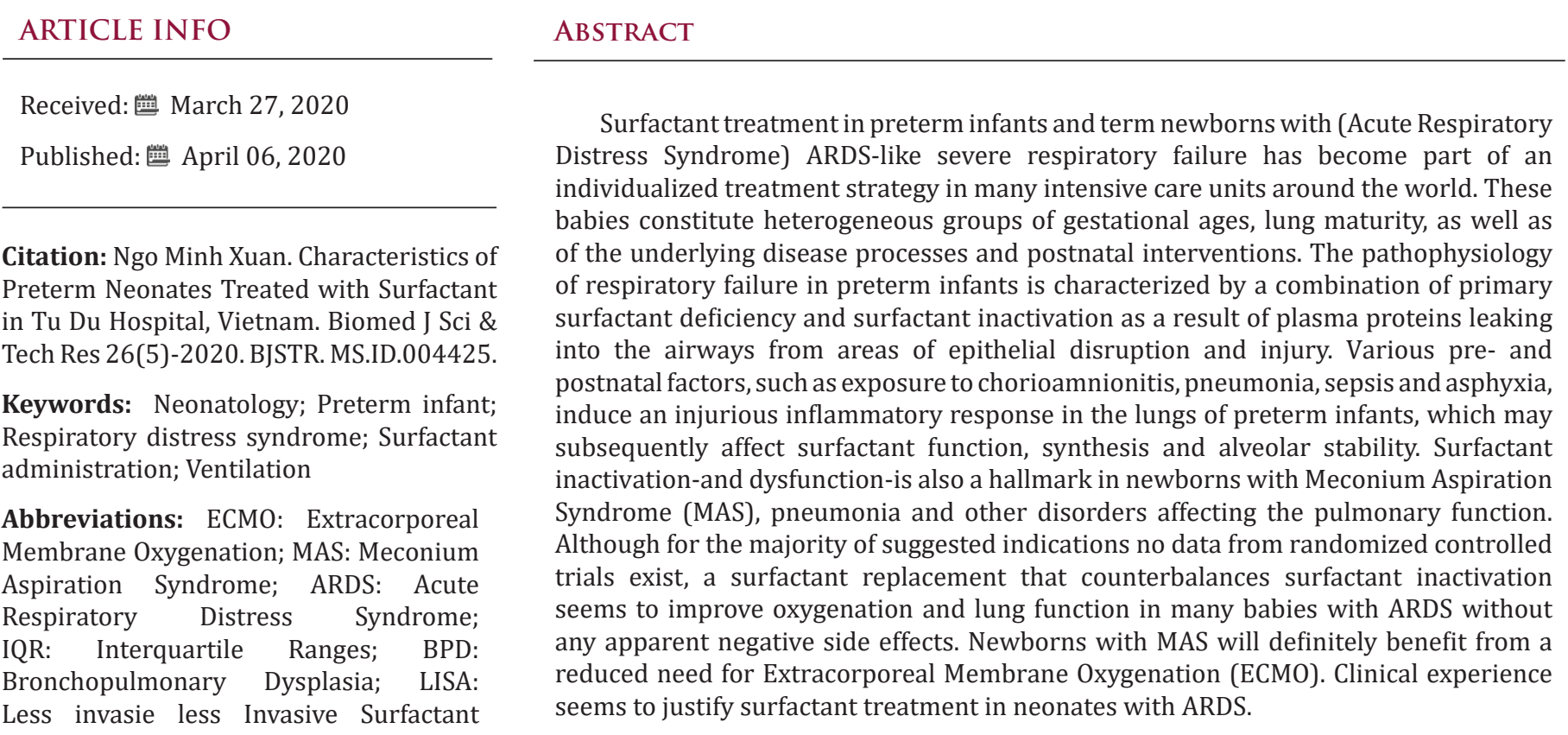

Administration: IVH: Intraventricular

Hemorrhage

\section{Introduction}

Treatment with exogenous surfactant has saved the lives of thousands of premature babies in the past few decades [1]. The therapeutic efficiency of a given surfactant preparation correlates with its lipid and protein composition (and other factors), but it is also highly dependent on the technique used for administration. It is important to use a delivery strategy that optimizes surfactant distribution into the pulmonary airways to maximize its beneficial effects [2]. In 2014, the Committee on Fetus and Newborn - American Academy of Pediatrics published a clinical report on the use of surfactant replacement therapy for respiratory distress in the preterm and term neonate [1]. Among several recommendations, the report stated that "the optimal method of surfactant administration in preterm infants has yet to be clearly proven". Unfortunately, the scientific literature provides conflicting and limited data regarding the methods or techniques of surfactant administration. The majority of studies were performed long ago and tested in more mature infants (gestational age $>28$ weeks), which does not reflect the population of preterm infants that actually undergo endotracheal intubation and surfactant treatment.

Moreover, respiratory care has changed substantially since these studies were conducted. Exogenous surfactant preparations must spread rapidly and efficiently into the air-liquid interface once instilled in the proximal airways, with the goal of achieving a homogenous distribution throughout the lungs. However, rapid administration of liquid into the lungs may elicit transient 
oxygen desaturation and bradycardia, or significant complications such as severe airway obstruction, pulmonary hemorrhage, pneumothoraces or pulmonary hypertension [3]. Therefore, surfactant should be administered according to a well-established protocol under the supervision of clinicians and respiratory therapists experienced in tracheal intubation, ventilator management and general care of the premature infant. The present article reviews the characteristics of preterm neonates treated with surfactant in Tu Du Hospital, Vietnam

\section{Materials and Methods}

This was a retrospective study in which a total of 426 preterm newborns less than 34 weeks gestation were studied. The study was carried in Tu Duc Hospital from August 2017 - July 2018. The inclusion criteria were designed to include newborn babies who were less than 34 weeks gestational age at the time of birth. The gestational age assessment was based on antenatal records and postnatal assessment based on expanded new Ballard scoring system. The babies with congenital malformations and the babies born to mothers with chorioamnionitis were excluded from the study. All preterm newborns less than 34 weeks gestation who satisfied the inclusion criteria were administered exogenous surfactant by endotracheal route $(4 \mathrm{~mL} / \mathrm{Kg}$ of the surfactant preparation equivalent to $100 \mathrm{mg} / \mathrm{Kg}$ of phospholipids) after resuscitation and stabilisation of the neonates shortly after birth. Further management of these babies was guided by their cardiorespiratory status and was as per the existing protocols in the neonatal intensive care unit. We report demographic and clinical characteristics variables using frequencies and proportions for categorical data and medians with Interquartile Ranges (IQR) for continuous data. Continuous normally distributed variables (such as birth weight and gestational age) were analysed using unpaired Student ' $t$ ' test. Various proportions of neonatal morbidity were analysed using Chi square test or Fisherss exact test when an expected cell value was $<5$.

\section{Results}

From August 2017 to July 2018, there were 1926 premature babies $\leq 32$ weeks admitted to the Tu Du Hospital's neonatal department. A total of 426 children (22.12\%) received surfactant treatment. There were 53 infants born with nCPAP that met the sampling criteria and were enrolled in the minimally invasive LISA group. Table 1 shows the average gestational age of the LISA group with less invasive technique was $29.1 \pm 1.9$ weeks. The average gestational age of the group using INSURE technique was $29.7 \pm 1.6$ weeks. The average gestational age of LISA group was lower than the INSURE group but the difference was not statistically significant, $\mathrm{p}=0.07$. Table 2 shows the birth weight in the LISA group was $1248.1 \pm 311.6$, lower than the birth weight in the INSURE group was $1308.5 \pm 309.1$. The difference is not statistically significant, $p$ $=0.32$. The smallest birth weight in the LISA group was $600 \mathrm{~g}$, the highest was $1800 \mathrm{~g}$. The smallest birth weight in the INSURE group was $800 \mathrm{~g}$, the highest in $1950 \mathrm{~g}$.

Table 1: Average gestational age.

\begin{tabular}{|c|c|c|c|c|}
\hline Technique & Mean \pm SD & CI 95\% & Min & Max \\
\hline INSURE & $29.7 \pm 1.6$ & $29.3-30.2$ & 26.1 & 32 \\
\hline LISA & $29.1 \pm 1.9$ & $28.5-29.6$ & 26.0. & 0.07 \\
\hline
\end{tabular}

Table 2: Weight at birth.

\begin{tabular}{|c|c|c|c|c|}
\hline Technique & Mean \pm SD & CI 95\% & Min & Max \\
\hline INSURE & $1308.5 \pm 309.1$ & $1223.3-1393.7$ & 1950 \\
\hline LISA & $1248.1 \pm 311.6$ & $1162.2-1334.0$ & 600 & 0.032 \\
\hline
\end{tabular}

The gender distribution of the two treatments was similar, with $50.9 \%$ of the boys in the LISA group being less invasive compared to $54.7 \%$ of the boys treated with INSURE, the difference was not Statistically significant with $p=0.69$ (Table 3). There was no difference in using sufficient prenatal steroids dose between 2 groups INSURE and LISA by less invasive technique, $p>0.05$. The caesarean group had a lower rate of invasive LISA (60.4\%) than the treatment with INSURE (56.6\%), the difference was not statistically significant with $\mathrm{p}=0.69$ (Table 4). The average CRIB score of the LISA group was $2.28 \pm 1.16$, the INSURE group was $2.07 \pm 1.45$. The average CRIB score of the LISA group was 0.2 points higher than the INSURE group, the difference was not statistically significant, $\mathrm{p}=0.42$ (Figure 1). According to Table 5, the average age of LISA in the INSURE group was $(243.49 \pm 13.6)$ minutes (equivalent to 4 hours \pm 13.6 minutes), the average age at the LISA in the LISA group was (204.53). \pm 13.6 ) minutes (equivalent to 3 hours 24 minutes \pm 13.6 minutes). The LISA group was implemented earlier than the INSURE LISA group. The difference was statistically significant $\mathrm{p}=$ 0.04 . 
Figure 1: CRIB score.

Table 3: The sex of preterm newborn.

\begin{tabular}{|c|c|c|c|c|}
\hline Sex & LISA & INSURE & OR (CI 95\%) \\
$(\mathbf{n = 5 3 )}$ & $29(50.9)$ & $7(54.7)$ & \multirow{2}{*}{$0.85(0.37-1.98)$} & $\boldsymbol{p}$-value \\
\cline { 1 - 3 } Male & $26(49.1)$ & $24(45.3)$ & 0.69 \\
\hline
\end{tabular}

Table 4: Corticoids using before birth.

\begin{tabular}{|c|c|c|c|c|}
\hline & $\begin{array}{c}\text { LISA } \\
(\mathbf{n = 5 3 )}\end{array}$ & $\begin{array}{c}\text { INSURE } \\
(\mathbf{n = 5 3 )}\end{array}$ & OR (CI 95\%) & \\
\hline Corticoids using before birth & & & \\
\hline No use & $28(52.8)$ & $24(45.3)$ & $0.59(0.21-1.62)$ & 0.31 \\
\hline Less dose use & $9(17.0)$ & $13(24.5)$ & $0.86(0.35-2.07)$ & 0.73 \\
\hline Full dose use & $16(30.2)$ & $16(30.2)$ & & 0.69 \\
\hline Delivery method & $21(39.6)$ & $23(43.4)$ & & \\
\hline Normal delivery & $32(60.4)$ & $30(56.6)$ & $0.37-2.00)$ & \\
\hline Caesarean delivery & & & \\
\hline
\end{tabular}

Table 5: The age of baby at time of procedure.

\begin{tabular}{|c|c|c|c|c|c|}
\hline Technique & Mean \pm SD & CI 95\% & Min & Max & p-value \\
\hline INSURE & $243.49 \pm 13.6$ & $216.3-270.7$ & 65 & 360 \\
\hline LISA & $204.53 \pm 13.6$ & $177.1-231.9$ & 50 & 360 \\
\hline
\end{tabular}

\section{Discussion}

Respiratory distress syndrome in preterm infants is a disorder caused by a primary deficiency of surfactant or surfactant in immature lungs, resulting in progressive, widespread alveolar collapse, resulting in early respiratory failure. Birth, which is an important cause of morbidity and mortality in preterm infants. Surfactant replacement therapy reduces the risk of death and complications of bronchopulmonary dysplasia (BPD) [4]. The combination of prenatal sterocorticoids, early postpartum NCPAP and alternative surfactant therapy improved outcomes for preterm neonates. There have been many studies on techniques of pumping surfactant into the lungs. Until now, the INSURE technique has been considered the standard in surfactant replacement therapy. However, with INSURE technique, endotracheal intubation is still needed to pump surfactant and consequently the child undergoes mechanical ventilation during the procedure. To minimize the child's exposure to invasive mechanical ventilation, clinicians have improved the technique of pumping surfactant into the lungs without the need for mechanical ventilation, called a minimally invasive surfactant (LISA - Less invasie less Invasive Surfactant Administration (MIST). 
Attempts to introduce surfactant into the lungs by aerosol spray or laryngeal mask have not shown clinical evidence [5]. A recommended minimally invasive technique is to open the glottis with a laryngoscope and insert a small catheter into the trachea. Surfactant is introduced into the lungs through this catheter. There have been many studies on the feasibility and effectiveness of this technique. Recently, Christin S and colleagues published in the journal Global Pediatric health Meta-analysis of low-invasive LISA technology that reduces the need for invasive mechanical ventilation in preterm neonates. The authors selected 3 studies of Kanmaz et al. [6-8] out of 219 published studies to be included in the analysis [9]. Author Mohamma dizadeh et al. [7] used 4F gastric catheter and used Magill forceps to insert catheter into trachea. Surfactant is pumped for 1 - 3 minutes. Kanmaz et al. [6] used a $5 \mathrm{~F}$ gastric tube and did not need Magill nipper to insert the gastric tube into the trachea.

The surfactant used is Poractant alpha and injects rapidly within 30-60 seconds [10]. Dargaville PA uses a vascular catheter and does not require Magill nipper to enter the trachea [11]. Authors Bao et al. [8] used a 16G vascular catheter and did not use Magill nipper to insert the catheter into the trachea. Surfactant is pumped for 3-5 minutes [12]. Author Wolfgang Gopel 2016 uses endotracheal tubes 2.5 and does not need Magill nippers [13]. According to author Cristina Ramos-Navarro, a small 5-6 F catheter is specially designed to pump surfactant without using Magill nipper [14]. In our study, 5 - 6 F gastric catheter was used and inserted directly into the trachea through laryngoscope without using Magill nipper. The advantage is that gastric catheters are readily available, inexpensive while vascular catheters are expensive, and specially designed catheters by author Cristina Ramos-Navarro are not available in Vietnam. As for the endotracheal tube 2.5 , the inner diameter of the tube is 2.5 $\mathrm{mm}$, the outer diameter is $4.1 \mathrm{~mm}$, the rest for children to breathe when doing small procedures, children breathe harder.

In addition, the gastric tube we use is hard enough to put directly into the trachea without using Magill pliers, simple technical manipulation. These are the advantages of a technique. Simple equipment easy to find, low cost and simple operation easy to carry out. There was no difference between the two groups in the study of primary features or prenatal risk factors, except that the CRIB score was higher in the LISA group, indicating a more severe clinical condition at baseline. In this study, the mean gestational age was $29.7 \pm 0.22$ weeks in the INSURE group and $29.06 \pm 0.26$ weeks in the LISA group, the difference was not statistically significant, $p$ $=0.065$. In the study of Cristina $\mathrm{R}$ et al., The average gestational age in the INSURE group was 29.1 weeks and 28.4 weeks in the LISA group, the difference was not statistically significant [14]. In the study of Bao et al. [8], the average gestational age of two groups of INSURE and LISAs was $29.3 \pm 1.6$ weeks and $29.1 \pm 1.5$ weeks, the difference was not significant. Statistically significant $p=0.54$ [12]. In the study of Mohammadizadeh Majid et al. [7], the average gestational age was higher in the INSURE group and the LISA (31 \pm 2 weeks, $30 \pm 2$ weeks, $p=0.2$ ] [13].

The mean gestational age in our study was nearly the same as the average gestational age of other studies that studied preterm infants under 32 weeks gestation. When we grouped gestational age groups by smaller groups, we found no difference in each gestational age group, especially the age group below 28 weeks. Babies under the age of 28 weeks are the subjects with worse and worse outcomes in those of higher gestational age, especially the effects of mechanical ventilation on immature lungs. Therefore, this age group is at particular risk for broncho pulmonary dysplasia. In addition, other organs are immature, so this subject is susceptible to systemic infections, pneumonia, arterial duct disease, necrotizing enterocolitis and retinopathy in preterm infants. There was no difference in the rates of caesarean births in the 2 INSURE groups and the LISA Regarding prenatal coticosteroids use, in the study of Cristina $\mathrm{R}$ et al., The rate of prenatal coticosteroids use in the INSURE group was $70 \%$ and $73 \%$ in the LISA group, the difference was not statistically significant [11].

In the study of Bao et al. [8], the use of antenatal coticosteroids 2 groups INSURE and LISA group was $93 \%$ and $89.4 \%$, the difference was not statistically significant $p=0.54$ [12]. In the study of Mohammadizadeh Majid et al. [7], the use of antenatal coticosteroids in the INSURE group and the LISA group was $89.5 \%$ and $84.2 \%$, $p=0.2$ [13]. In our study, the rate of adequate use of antenatal corticoids was lower than that of other studies but no difference was found between the two LISA groups and the INSURE. The use of antenatal corticoids for pregnant women at risk of preterm birth contributes to improved adverse outcomes for preterm neonates. The effect of antenatal corticoids reduces the incidence and severity of respiratory endothelial respiratory depression in preterm neonates. In a Systematic review of Robert D 2017 on the Cochrane Library, treatment with prenatal corticosteroids (compared to placebo or no treatment) was associated with a reduction in the most serious adverse outcomes associated with preterm birth, including: perinatal mortality (average risk ratio) RR) 0.72, 95\% confidence interval (CI) 0.58 - 0.89; participants $=6729$; research = 15; $\mathrm{Tau}^{2}=0.05 ; \mathrm{I}^{2}=34 \%$; moderate-quality); neonatal mortality (RR 0.69, 95\% CI 0.59 - 0.81; participants = 7188; study = 22), RDS (average RR 0.66; 95\% CI 0.56 - 0 , 77; participants = 7764; research = 28; $\mathrm{Tau}^{2}=0.06 ; \mathrm{I}^{2}=48 \%$; moderate-quality); Medium / heavy RDS (RR average 0.59, 95\% CI 0.38 - 0.91; participants = 1686; studies = 6; $\mathrm{Tau}^{2}=0.14 ; \mathrm{I}^{2}=52 \%$ ); intraventricular hemorrhage (IVH) (RR average $0.55,95 \%$ CI $0.40-0.76$; participants $=6093$; studies $=16$; $\mathrm{Tau}^{2}=0.10 ; \mathrm{I}^{2}=33 \%$; moderate -quality), necrotizing enterocolitis (RR 0.50, 95\% CI 0.32 - 0.78; participants = 4702; studies $=10$ ); mechanical ventilation is required (RR $0.68,95 \%$ CI $0.56-0.84$; participants = 1368; research $=9$ ); and systemic infection in the first 48 hours of life (RR 0.60, 95\% CI $0.41-0.88$; participants = 1753; studies $=8$ ) [14]. 


\section{Conflicts of Interest}

There are no conflicts of interest to declare.

\section{Financial Support and Sponsorship}

Nil.

\section{References}

1 Polin RA, Carlo WA, Committee on F, Newborn, American Academy of P, et al. (2014) Surfactant replacement therapy for preterm and term neonates with respiratory distress. Pediatrics 133(1): 156-163.

2 Jobe $\mathrm{AH}$ (2006) Mechanisms to explain surfactant responses. Biol Neonate 89(4): 298-302.

3 Tarawneh A, Kaczmarek J, Bottino MN, Santanna GM (2012) Severe airway obstruction during surfactant administration using a standardized protocol: a prospective, observational study. J Perinatol 32(4): 270-275.

4 Aguar M, Cernada M, Brugada M, Gimeno A, Gutierrez A, et al. (2014) Minimally invasive surfactant therapy with a gastric tube is as effective as the intubation, surfactant, and extubation technique in preterm babies. Acta Paediatr 103(6): e229-233.

5 Finer NN, Merritt TA, Bernstein G, Job L, Mazela J, et al. (2010) An open label, pilot study of Aerosurf(R) combined with nCPAP to prevent RDS in preterm neonates. J Aerosol Med Pulm Drug Deliv 23(5): 303-309.

6 Kanmaz HG, Erdeve O, Canpolat FE, Mutlu B, Dilmen U, et al. (2013) Surfactant administration via thin catheter during spontaneous breathing: randomized controlled trial. Pediatrics 131(2): e502-509.

ISSN: $2574-1241$

DOI: 10.26717/BJSTR.2020.26.004425

Ngo Minh Xuan. Biomed J Sci \& Tech Res

(C) This work is licensed under Creative Commons Attribution 4.0 License

Submission Link: https://biomedres.us/submit-manuscript.php
7 Mohammadizadeh M, Ardestani AG, Sadeghnia AR (2015) Early administration of surfactant via a thin intratracheal catheter in preterm infants with respiratory distress syndrome: Feasibility and outcome. J Res Pharm Pract 4(1): 31-36.

8 Bao Y, Zhang G, Wu M, Ma L, Zhu J, et al. (2015) A pilot study of less invasive surfactant administration in very preterm infants in a Chinese tertiary center. BMC Pediatr 15(21).

9 Lau CSM, Chamberlain RS, Sun S (2017) Less Invasive Surfactant Administration Reduces the Need for Mechanical Ventilation in Preterm Infants: A Meta-Analysis. Glob Pediatr Health.

10 Dargaville PA, Aiyappan A, De Paoli AG, Kuschel CA, Kamlin CO, et al. (2013) Minimally-invasive surfactant therapy in preterm infants on continuous positive airway pressure. Arch Dis Child Fetal Neonatal Ed 98(2): 122-126.

11 Ardell S, Pfister RH, Soll R (2015) Animal derived surfactant extract versus protein free synthetic surfactant for the prevention and treatment of respiratory distress syndrome. Cochrane Database Syst Rev 8.

12 Gopel W, Kribs A, Hartel C, Avenarius S, Teig N, et al. (2015) Less invasive surfactant administration is associated with improved pulmonary outcomes in spontaneously breathing preterm infants. Acta Paediatr 104(3): 241-246.

13 Ramos Navarro C, Sanchez Luna M, Zeballos Sarrato S, Gonzalez Pacheco N (2016) Less invasive beractant administration in preterm infants: a pilot study. Clinics (Sao Paulo) 71(3): 128-134.

14 Jean M, Guinn D (2018) Antenatal corticosteroid therapy for reduction of neonatal respiratory morbidity and mortality from preterm delivery.

$\begin{array}{ll}\text { BIOMEDICAL } & \text { Assets of Publishing with us } \\ \text { RESEARCHES } & \text { - Global archiving of articles } \\ & \text { - Immediate, unrestricted online access } \\ & \text { - Rigorous Peer Review Process } \\ & \end{array}$

